\title{
Historia de la Fundación del Hospital y Convento de Nuestra Señora de la Almudena del Cuzco
}

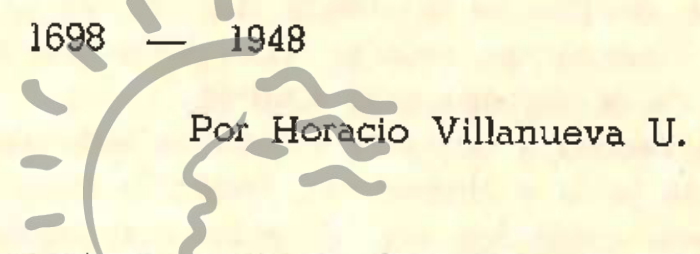

Consecuentes con nuestro incesante empeño de dar a conocer los sugestivos aspectos de nuestro riquísimo pasado, y seguros como estamos de que la Historia del Cuzco sólo podrá sescribirse ínlegra cuando una serie de estudios monográficos, confeccionados Ponciduidadosandedicación, haya logrado presentar los numerosos aspectos parciales de su abundonte acervo, queremos ofrecer ahora un capítulo casi ignorado de su Historia colonial: el del establecimiento de los reliogiosos de Belén y la tundación de su hospital $y$ convento del Cuzco, en la oportunidad de su $250^{\circ}$ aniversario, para lo que hemos entresacado datos de nuestra desordenada colección de apuntes recogidos con desvelo $y$ amor.

A) hacerlo, repetimos, nos guía el afán de divulgar algo de lo mucho que en nuestra ciudad merece atención $y$, sobre todo, el deseo de solazarnos en la evocación admirativa de los hombres y los he chos que hacen su interesante historfa. 


\section{LOS BETHLEMITAS EN EL CUZCO}

Fué durante el gobierno episcopal del llustrísimo Dr. D. Manuel de Mollinedo y Angulo, XIVo Obispo del Cuzco (1673-1699), cuando se produjo la llegada de los hermanos de Belén, precisamente en la épo. ca en que merced a la munificencia de tan digno prelado iba transformándose en gran urbe colonial.

Cuenta el Padre García de la Concepción (1) que hallándose los Padres de Belén en Lima empeñados en la construcción de un nuevo local, pues, su hospital primitivo llamado del Carmen había sido arruinado por el terremoto de 20 de octubre de 1867 (2), determinó el Prefecto Mayor de la Orden Fray Alonso de la Encarnación que saliesen de Lima los Padres Miguel y Antonio de la Concepción para que recogiesen limosnas en todo el Virreynato que sirvieran para acrecentar los fondos de la construcción aludida.

Ingresaron a la sierra estos aos religiosos en pos de su misión por la vía de Jauja y Huamanga, llegando en el año de 1690 al Cuzco donde fueron recibidos con singulares muestras de contento y distinción por parte de las autoridades de todo el vecindario, habiendo sido alo jados en el Convento de Santo Domingo.

Quizo entonces el señor Obispo Mollinedo aprovechar la presencía de estos dos hijos de Belén para tratar con ellos de la fundación de un hospital Bethlemitagen lelcuzddi, habieadootenido la intención de entregarles el Real Hospital de indios de la ciudad.

Fray Miguel de la Concepción, despues de oir al Obispo, parece qu e no encontró oportuno el proyecto y le manifesló que creía difíciles

(1) García de la Concepción, Fr. José. -HISTORIA BETHLEHEMITICA. - Vida exemplar, y admirable del venerable siervo de Dios, y Padre Pedro de San Joseph Betancur, fundador de el regular Instituto de Bethlehen en las Indias Occidentales, elc.- Sevilla, 1723.- Libro IIl, pgs. 50-54.

(2) Cuéntase que fueron desastrosos los temblores de este año en LIma, que cayeron por tierra casi todos los templos y conventos de la ciudad, y los muchos edificios que quedaron maltratados sucumbieron con la coplosa lluvia que sobrevino como remate de la gran calamidad.- Kachmann, Carlos I. - Temblores y terremolos de Li. ma.- "El Comercio" de Lima, 18 de enero de 1935.- Valega, José M.- El Virreynato del Perú.- Lima, 1939, pgs. 383-412). 
nuevas fundaciones de su Religión por cuanto parecía pendiente el pleito que en Madrid sostenía Fray Rodrigo de la Cruz, Prefecto General, por el paso de los Breves Apostólicos que reformaban la Orden de Belén, afirmando además que, por esta razón, era imposible que el Prefecto Mayor de Lima Padre Alonso de la Encarnación, diera licencia alguna. El Obispo, que era varon de mucha empresa, respondió haciendo que en su nombre y en el de los dos cabildos se escribiese al Padre de la Encarnación suplicando su consentimiento. Convino pronto el Prefecto en la nueva fundación, siempre que fuere obtenida la licencia del Virrey y solicitada, finalmente esta última, fué concedida con relativa iacilidad.

Parecía, pues, ya allanado el camino; más, el Padre de la Encarnación, que no había accedido a ella de muy buen grado, quizo impedirla pidiendo por escrito al señor Obispo Mollinedo que fuese postergada. Grande fué el disgusto que por ello se llevó el celoso Obispo del Cuzco y el muy cátólico vecindario que desesperaban por ver establecido el Instituto de Belén en la ciudad, de cuya piadosa obra se esperaba fundadamente múltiples beneficios.

Los públicos y desabridos comentarios a que dió lugar la censurable actitud del Prefecto Mayor, obligaron a Fray Miguel de la Concepción a viajar apresuradamente desde el Cuzco a Lima, porque creía que hablando con el Padre de la Encarnación, serían allanados los últimos impedimentos referentes a lac fundación.et andaba Fray Miguel tan ancioso de obtener el gostrer permiso que el largo y penoso viaje fué hecho solamente en trece dias. Mas, el Padre Prefecto Mayor se negó a recibirlo ordenándole que regresara a su destino, pues, había viajado sin permiso. Fray Miguel no quizo volver al Cuzco sin explicar los motivos de su apresurado viaje $y$ admitido luego en el Convento, pronto pudo darse cuenta que eran motivos más importantes los que mantenían el disgusto del Prefecto Mayor $y$ de toda la comunidad Bethlemítica. Veamos cuáles eran esos motivos.

Podríamos decir que se trataba de un impase en el seno de la misma Institución. Cuando el Padre Rodrigo de la Cruz logró obtener en España la aprobación de los Breves Apostólicos de su Orden, dispuso que viniese con ellos a América Fray José de la Soledad a quién ins. truyó para que diese la profesión de los votos religiosos al Padre Pre fecto Mayor de Lima quien debería, a su vez, otorgarla a los demás religiosos. Fray Alonso de la Encarnación, que hacían trece años ejercía la Prefectura, no quizo admitir esta comisión argumentando que los Breves no habían sido pasados por el Consejo. Como el comisionado 
Padre de la Soledad sólo estaba autorizado a dar la profesión a la persona del Prefecto Mayor de Lima y éste no quería admitirla, no pudo, como lógica consecuencia, producirse la profesión de los demás relí giosos, originándose entonces un serio conflicto que mantenía el disgusto de todà la comunidad. Fué entonces necesario que se recurriese al señor Arzobispo de Lima quien, en uso de atribución legal, privó de la Prefectura Mayor al Padre de la Encarnación y nombró en su reemplazo a Fray Blas de Santa María, Prefecto del Hospital de Nuestra Señora de la Piedad en la Villa de Cajamarca. Eil nuevo Prefecto Mayor admitió la profesión y habiéndola otorgado después a los demás relígiosos, quedó así solucionado el enojoso incidente.

Este conflicto, como era natural, impidió a Fray Miguel de la Con. cepción decidir en Lima el asunto de la fundación del hospital del Cuzco, la que tuvo que ser postergada hasta un poco después.

\section{LA FUNDACION}

Digno émulo del llustre Obispo Mollinedo era su sobrino el li cenciado D. Andrés de Mollinedo que viviera con él imitando su largueza yayudándolo con esplendidez en la obra de embellecimeinto del Cuzco.

Muchos son los beneficios que la ciudad debe a tan eminente religioso. Cura del Hospital de Naturales hacia fines del siglo XVII, vió que una gran parte del vecindario indígena de su Parroquia, que vivía "al otro lado del río", en el barrio que llamaban de la "Chimba", estaba imposibilitada frecuentemente de recibir oportunos auxilios religiosos y de concurrir a misa y doctrina los días de precepto, por la perjudicial distancia que separaba sus casas de la Iglesia Parroquial y. movida de piadoso celo, se propuso construír una Iglesia en dicho apartado lugar. Pidió entonces licencia para obra tan pía y la obtuvo del Obispo el 4 de setiembre de 1683 (documento $\mathrm{N}^{9}$ 1).

Construído el edificio, pensó el Obispo en una imagen a quién fuera dedicada la nueva Iglesia, y encargó al escultor indio Juan Tomás la ejecución de una copia de Nuestra Señora de la Almudena de Madrid, lugar donde el ilustre Prelado había sido Párroco antes de alcanzar la dignidad episcopal en América. La obra fué lograda a tanta perfección que Mollinedo encargó al escultor fuese incrustada en la cabe- 
za de la imagen una pequeña astilla de la Virgen madrileña que conservaba a manera de preciosa reliquia (3).

La Virgen, finalmente, lué colocada en su flamante santuario el $1^{\circ}$ de mayo de 1686, fecha que después solía festejarse anualmente, pues, coincidía co nel aniversario de la consagración del Ilustrísimo Obispo. habiéndose encargado del culto y cuidado de la Iglesia, desde 1689, la "Hermandad de Esclavitud de Nuestra Señora de la Almudena", cofradía organizada con tal fin por el Licenciado Mollinedo (4).

Esta nueva casa y santuario que sirvieran también de lugar de descanso y recreo al Ilustrísimo Obispo, fueron dedicados después por él mismo para Hospital Bethlmmítico del Cuzco, a pesar de que su funda-

Licenciado D. Andrés "de Mellinedoin (1635-1712), benemérito fundador de la Almudena y San Pedro del Cuz. co.

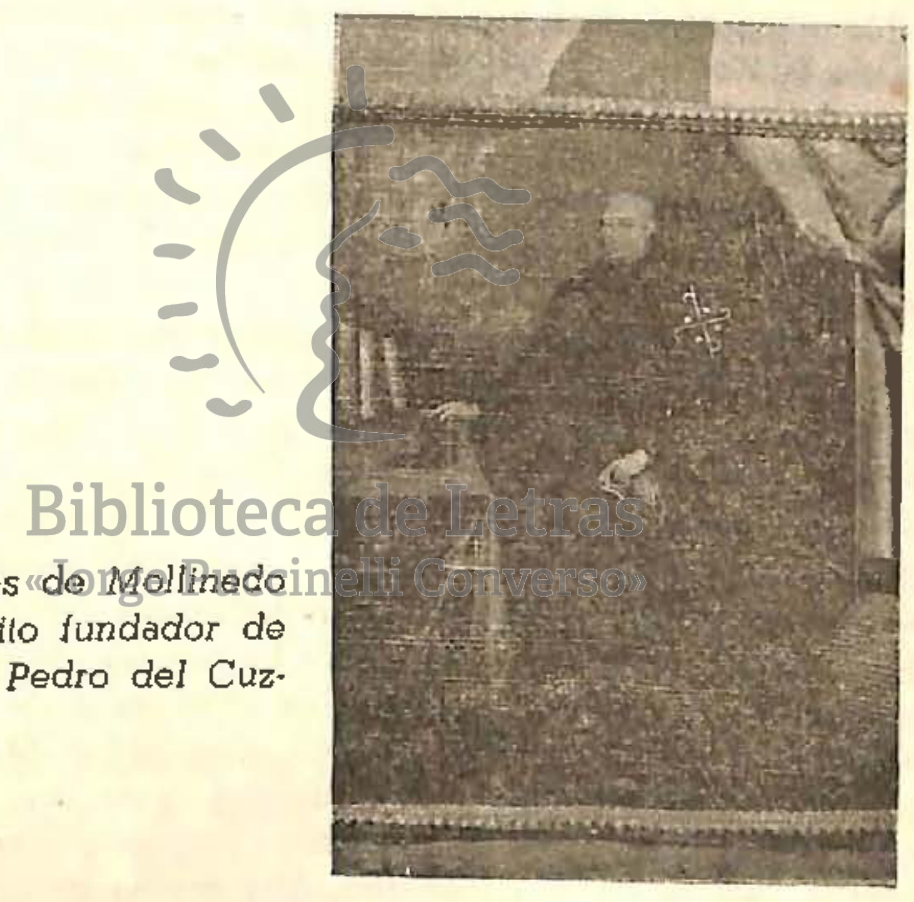

(3) A este escultor cuyo apellido materno es TURYO TOPA, se le cree, sin fundamento histórico alguno, autor del famoso púlpito de San Blas.- Conviene no olvidar al respecto que en los "Anales del Cuzco" 1600-1750, pg. 201, se afirma que los púlpilos de Belén y San Blas, tueron traídos por el Obispo Mollinedo.

(1) CONSFTITUCIONES DE IA HERMANDAD DE LA. EFCLAVITUD DE N. SENORA DE LA ALMUDENA de la Parrochia del holpital de Naturalef defta ciudad del Cuzco.- 1699. 
dor en un principio quizo consagrar el lugar, en lorma permanente y exclusiva, al culto de la celebrada imagen (5).

Fué el Padre Miguel de la Concepción quién, en vista de que no era posible que su Orden recibiera el Hospital Real de la ciudad, por nallarse sus rentas muy disminuídas, pidió al Obispo, interesado en el establecimiento de los Bethlemitas en el Cuzco, que les cediera el Santuario y Casa de la Almudena para su hospital y convento, los que habían de ser dedicados a sacerdotes enfermos y pobres $y$ a índios con valescientes, cuestión en la que convinieron el Obispo y su sobrino el generoso fundador.

Hacia entonces, solucionado ya el conflícto en el seno de la Orden Bethlemítica en la forma que hemos narrado anteriormente, el mismo $\mathrm{Pa}$. dre de la Concepción se interesó por la fundación ante el Prefecto General de la misma Fray Rodrigo de la Cruz, recién llegado de España a Lima, y éste, obtenidas las respectivas licencias del Virrey y la Audiencia, $F$ dispuso que bajo su dirección salieran 10 religiosos a fundar el hospital y convento del Cuzco, arribando a la ciudad el 29 de junio de 1648.

Grande fué el alborozo con que el vecindario celebró la llegada de la tan deseada nueva Orden. "Todos las calles por donde pasaron los religiosos y su acompañamiento, dice el P. García de la Concepción, estaban adornadas de multiutd de Arcos triunfales, cuyo elevado, y magestuoso artificio indicaba la subida estimación, con que franqueban la entrada los ciudadanos a Paquella eddinumiáar Yenerable. En los balcones, y ventanas resonaban concertadísimos instrumentos músicos, $Y$ dulcícisimas voces; en cuyos ecos se percibió el cordial júbilo, con que admitía la ciudad del Cuzco a los profesores de aquel nuevo Instituto de caridad. Las campanas de la Catedral y demás iglesias pregonaron con grandes repiques esta entrada; para más solemnizarla con festivo estruendo. Con esta plausible conmoción llegaron a la Iglesia de Nuestra Señora de la Almudena, que era su destinada habitación y allí

(5) Una de las cláusulas de las citadas Constituciones dice al respecto: "Iten que en ningún tiempo la dicha Iglesia, Imagen, ni casa se puedan enajenar por la hermandad, Patrón, ni otro persona alguna pasando a comunidad de Regulares, ni a la Congregación de San Felipe Neri, ni para fundar en ella ningún convento, colegio ni noviclado, ni Beaterio que con esa calidad la ha cedido, cede y dona nuevamente el dicho Lcdo. D. Andrés de Mollinedo, y si acaso se enajenase, la dicha enajenación sea nula $y$ de ningún valor". 
renovaron las finezas, con que los aplaudian. El señor Obispo, y su Eclesiástico Cabildo estaban prevenidos en el templo; y cuando sintieron su llegada, salieron con Palio a recibirlos a la puerta; y habiendo entrado con este solemne aparato en la Iglesia, recibió el General, y su Comunidad Agua Bendita de mano de su Ilustrísima. y tomaron la posesión de aquella Santa Casa (6).

La escritura de donación del Santuario, casa y bienes de la Almudena a los Padres de Belén, fué firmada por el Obispo el 29 de agosto de 1698 , y la posesión judicial les fué otorgada en la persona del Reverendo Padre Prefecto General de la Orden, Fray Rodrigo d ela Cruz, por D. Juan Fernando Calderón de la Barca, Justicia Mayor del Cuzco, el primero de setiembre del mismo año (7). - (Documento № 2). La licencia del Rey para la teferida fundación fué otorgada por Cédula Real dada en Madrid el 17 de agosto de 1700 (8). - (Documento N9 3).

Consta, además, por la cláusula $10^{a}$ de la citada escritura que reproducimos, que un poco antes de la llegada de los Padres al Cuzco, ya se planeaba la construción del templo actual, edificio que años después fué concluído, pues, la consagración de sus campanas corrió a cargo del Obispo D. Bernardo Serrada, en 30 de marzo de 1728 (9).

(6) García de la Concepción.- Ob. Cit. III. pg. 57.- Es curiosa la forma cómo Esquivel ${ }^{\circ}$ Nayia en sus célebres Anales, anota la llegada de los PP. de Belén. La entrada de los religiosos Bethlemitas en esta ciudad,odice, Pué domihóceridersiono, día de los gloriosos apóstoles san Pero y san Pablo, a las cuatro de la tarde, viniendo con ellos su general fray Rodrigo de la Cruz, con acompañamiento de ambos Cabildos y de los más ilustrados ciudadanos y vecinos, desde la parroquia de la gloriosa santa Ana, estando las calles bien adornadas de tapicerías y pasadizos que llaman arcos (pero no triuntales) ni música en los balcones, como pone la HISTORIA BETHLEMITICA".- Anales del Cuzco.- I600-1750.- Lima, 1901. Pg. 195.

(7) Archivo del Colegio Nacional de Ciencias del Cuzco,- Leg. 13; Cuad. 1.

(8) Archivo Citado.- Leg. 17.

(9) Archivo Cit. Leg. 13, N! 1. 


\section{COLOFON}

La historia de la Virgen de la Almudena comienza con la su original. Dícese que el templo de esta imagen fué el primero que existió en Madrid y que al producirse la conquista de España por los moros, sus devotos, cumpliendo el decreto de don Raimundo, Arzobispo de Toledo, la enterraron para preservarla de la profanación. Años después fué encontrada el 9 de noviembre de 1805, al desplomarse uno de los muros de la Alhondiga o Almudiht que establecieron los africanos durante la ocupación.

Este último hecho, con otro milagro, aparece narrado en el cuadro de la misma Virgen que exorna la Catedral del Cuzco y cuya leyenda parcialmente dice así: "Imagen de Santa María Real de la Almudena, a cuyo milagroso original venera católica la imperial Corte de Madrid, en el más antiguo de los templos en que los reales ánimos de nuestros católicos monarcas veneran con fiel reconocimiento su celestial amparo. Hallándose los moradores de Madrid sitiados por el rey moro de Toledo, la segunda vez que los africanos pretendieron señorear a España, apretó el asedio co ntal viveza de armas que afligidos los cristianos de la hambre trataron de hacer, a pesar de su valor, la entrega; pero cuando más dados al desconsuelointentaban pōr miedo de su esclavitud redimir las vidas de la fiereza de aquel bárbaro, vieron que desgajado un lienzo del muro caía de el lanta abundandiar de"trigo que bastó a sacarlos del aprieto obligando con este socorro al enemigo a que con descrédito de sus armas levantarse el cerco. Reconocieron los cristianos la muralla y hallaron en uno de sus cubos a esta señora que tomó desde entonces de la Virgen de la Almudena, porque el trigo que piadosa les favoreció le recibían los de Madrid por almudes; estuvo oculta en este paraje 572 años que corrieron desde que un sacerdote anciano le ocultó en él para librarla de la infidelidad de los moros hasta que con esta maravilla hizo patente a los españoles su hermosura........" "Trajo esta santa imagen desde Madrid el Iltmo. Sr. Dr. D. Manuel de Mollinedo y Angulo, Obispo de esta ciudad y en memoria de la fervorosa devoción con que la venera mando delinear esta copia año de $1698^{\prime \prime}$.

Hay que suponer que lo que trajo el Sr. Obispo Mollinedo al Cuzco, fué una copia de la venerada Imagen ya que el original se conserva actualmente en Madrid. La Virgen Cuzqueña, que indubitablemente 
constiluye la obra maesira del escultor juan Tomás, ya hemos visto cuando fué hecha y colocada.

En cuanto a los fundadores de su Santuario, réstanos solamente decir que el Obispo falleció el 26 de setiembre de 1699, y su sobrino, el Ilustre Licenciado D. Andrés de Mollinedo, el 17 de noviembre de 1712 . habiendo sido enterrado en la Almudena; reza en el retrato que conserva su antigua Parroquia del Hospital de Naturales, hoy San Pedro del Cuzco.

Tuvo todavía tiempo el generoso mecenas de ver florecer su devota fundación en manos de los caritativos hijos de Belén.

\section{DOCUMENTOS}

\section{(No i) \\ LICENCIA PARA LA CONSTRUCCION DE LA IGLESIA SEMIPARROQUIAL DE $N$ S. DE LA ALMUDENA}

Iltmo. Señor.

El Licenciado D. Andrés de Mollinedo cura de In Paroquia del Hospital de los naturales de estadiraed. Digo qué como a V lita. le cons-

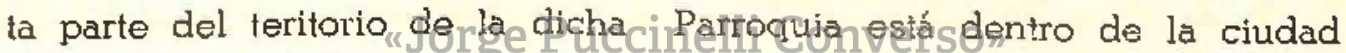
y lo restante en los confines de ella pasado el río conjunto con la de Santiago donde está la población de los Indios y ha estado descle la fundación de esta ciudad, y de poco tiempo a esta parte han vuelto a reedificarse sus casas $\mathrm{y}$ se ha acrecentado mucho el número $\mathrm{y}$ vecindadi de ellas y por esta causa es más frecuente la administración de los Santos Sacramentos en aquel lugar y porque la Iglesia Parroquial está en el mismo Hospital dentro de la ciudad y es mucha la distancia desde ella a los dichos confines de la dicha Parroquia donde está la re. ferida población de los Indios se lleva con incidencia el Beático a los enfermos atravezando las calles y algunas de ellas inmundas y no sin peligro de noche, especialmente en el invierno, de los accidentes que pueden acontecer y porque los Indios y demás personas que habitan aquellas partes por no dejar sus casas solas en parte tan apartada del comercio y concurso de la ciudad expuestas. a que las roben ladrones dejando de ir a oir misa y la doctrina los días de precepto, y así mismo muchas mujeres pobres por no tener vestido decente con que venir a la 
ciudad, no la oyen, y así para el que el Beático se administre con la decencia y reverencia que conviene como para que más cómoda y prontamente acuda el Sacerdote a las confesiones y para que se eviten los demás inconvenientes referidos, tengo determinado edificar una Iglesia a mi propia costa en aquel lugar para que esté colocado en ella el Santísimo Sacramento, y guardada la extrema unción. De que tengo dada cuenta a V. Ilta. y porque tengo entendido que tierie V. Ilta. bien vista, $\mathrm{Y}$ deliberada esta materia con madura consideración para que se ponga en ejecución la dicha fábrica.

A V. llta. pido y suplico que por lo que le toca se sirva de concederme licencia para la creación de dicha Iglesia pido justicia etc.

\section{Ldo. D. Andrés de Mollinedo.}

En la ciudad del Cuzco a cuatro días del mes de septiembre de mil seicientos ochenta $y$ tres el Iltmo. señor Doctor Don Manuel de Mollinedo y Angulo mi señor Obispo de ella del consejo de su Magestad habjendo visto esta petición - Dijo que habiéndose propuesto lo contenido en ella el Ldo. Don Andrés de Mollinedo Cura de la Parroquia del Hospital de log inaturales de esta ciudad su Ilta. atentamente reconoció por su propia persona la distancia que hay de la Iglesia Parroquial de dicha Parroquila a la porción Oque del "distrito y territorio de ella está en los confines de esta dicha ciudad pasado el río, y la grande población y número de Indios que hay en aquella parte, y los parajes inmundos, y peligrosos por donde es forzoso que pase el dicho Cura con el Santísimo Sacramento para administrarle a los enfermos, y la grande incidencia de pasar po rellos, y los inconvenientes que se pueden ofrecer de noche por varios accidentes especialmente en el invierno. $Y$ porque para que se reparen y bien, $Y$, más cómoda $Y$ prontamente se administren los Sagrados Sacramentos el medio más eficaz es el que fabrique otra Iglesia en el lugar que tiene elegido el dicho Cura que es el que hay más a propósito, usando de la potestad ordinaria que por derecho le compete, y por lo que a ella toca, concedia y concedió licencia para la erección de la dicha Iglesia para que en ella se coloque el Santísimo Sacramento, y se guarde la extrema unción para la más fácil، y pronta administración a los enfermos, y para que en ella se celebre el Santo sacrificio de la Misa para que la oigan los Indios y demás personas que habitan en aquella parte por constarle a 
su Ilta, que por no dejar solas sus casas en parte tan apartada del comercio y concurso de la ciudad expuestas a que las roben dejan de oirla y de ir a la doctrina cristiana los días de precepto, y ser cierto que mucha gente pobre vergonzante deja de oirla por no tener vestido decente con que bajar a la ciudad, con tal que las demás funciones se hagan en la Iglesia Parroquial que está en el dicho Hospital. I por esta razón de haber de estar colocado en la dicha Iglesia que se ha de fabricar el Santísimo Sacramento y haberse de decir Misa en ella para el efecto referido desde luego le concedía y concedió los privilegios, e inmunidades del que debe gozar conforme a derecho: así lo proveyó, y firmó su Ilta.

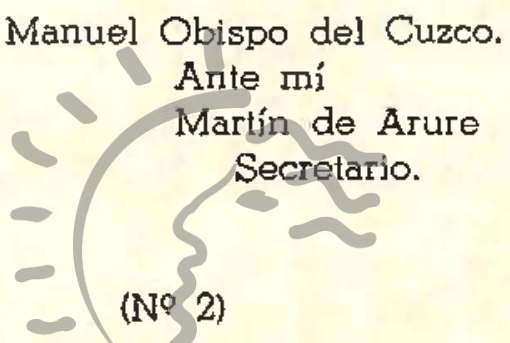

DONACION DEL SANTUARIO. CASA Y BIENES DE NUESTRA SENORA DE' LA ALMUDENA A.LA RELIGION BETHLEMITICA POR EL OBISPO DON MANUEL DE MOLLNEEOQ ANGULO Y $Q O_{R}$ EL LDO. DON "J ANDRES DENMOLLNEDOSO "

En la Gran Ciudad del Cuzco del Perú a veinte y nueve días del mes de agosto de mil seis cientos y noventa y ocho años ante mí el escribano y testigos estando en las casas episcopales parecieron el Iltmo. Señor Doctor Don Manuel de Mollinedo y Angulo obispo de esta ciudad y su obispado del Consejo de su Magestad y el Licenciado Don Andrés de Mollinedo su sobrino cura propio de La Parroquia del Hospital de los naturales de esta ciudad y Comisario del Santo Oficio de la Inquisición en ella y su partido a quienes doy fe que conozco I dijeron que por cuanto reconociendo cuán del servicio de Dios nuestro Señor $y$ de su agrado era el que en el Santuario y casa de Nuestra Señora de la Almudena que está en la otra banda de la dicha Parroquia del Hospital de las naturales que edeficó a su costa el dicho Licenciado Don Andrés de Mollinedo, se funde la Hospitalidad de señores clérigos Sacerdotes, pobres enfermos y la convalescencia de Indios y que los Padres Belemitas según su Instituto se habían dedicado a este ser- 
vicio y ejercicio por cartas que su Señoría y su llta. se sirvió de escribir al Rmo. Padre fray Rodrigo de la Cruz General de la dicha orden lo envió a llamar ofreciéndole dar dicha casa y Santuario para dicho efecto. I su Reverendísima mediante dicha promesa vino a esta ciudad con algunos religiosos que le acompañaron y así para que cuanto antes tenga efecto dicha fundación -- Otorgaron que hacían Gracia y Donación Intervivos y partes presentes con las insignuaciones y firmezas en derecho para su validación necesarias a la dicha Religión de Belemitas $y$ en su nombre al dicho Rmo. Padre fray Rodrigo de la Cruz, su General que está presente, del dicho Santuario y Casa de Nuestra Señora de la Almudena, para la dicha fundación de dicha Hospitalidad de señores clérigos Sacerdotes pobres y enfermos y para convalecencia de Indios con las calidades y condiciones siguientes:

1.- Lo primero que el nombro del silio y de la Imagen nunca se ha de mudar porque siempre se ha de-llamar Nuestra Señora de la Al. mudena

2.- Lo segundo que no se ha de derribar cosa ninguna de la casa que hay hoy sino es que sea necesario para su uso, o mejorándola en la fábrica para su duración y permanencia según la necesidad e injuria de los tiempos

3.- Lo tercero que êl aguadedas Pitas de adentro siempre ha de correr afuera sus remanentes para el Pueblo: I la Pila que está en la plazue. la enfrente de"la folesia del Nuestra Sefolahla de correr contínuamente agua para el Pueblo

4.- Lo cuarto que todos los días de fiestas de Indios y españoles y los Domingos siempre ha de haber Misa para que la oiga la gente del Pueblo que no ha podido ir a la Iglesia principial por lo cual se ha de decir, a hora competente que solo por esto se hizo la dicha capilla porque como vive en aquel Barrio retíado mucha gente pobre la más se quedaba sin oir Misa principalmente en tiempo de Aguas, y esta Misa se ha de costear la limosna de los efecios de la Cofradía mientras no hubiere renta impuesta para este efecto como hasta aquí se ha costeado

5.-Lo quinto que respecto de que los dichos religiosos Belemitas no admiten hacerse cargo de la administración de la Cofradía que está fundada en la conformidad que consta de su erección en dicha capilla de Nuestra Señora de la Almudena porque no le sirva de embarazo para los ministerios de su Instítuto y de menoscabo a las limosnas que han de pedir para la curación y sustento de los en- 
fermos obligándose indispensablemente a solicitar y cobrar las limosnas que contribuyen los esclavos de Nuestra Señora y así se ha de nombrar un Mayordomo clérigo o secular, por los mismos hermanos de la Cofradía en cuyo poder han de entrar las limosnas que juntaren y el procedido de las rentas que en adelante tuvieren y ha de ser obligación de los dichos religiosos Belemitas dar todas las alhajas y ornamentos que al presente tiene Nuestra Señora y hubieren recibido o recibieren cuando les entregue la casa para la fiesta y funciones cotidianas que tuviere dicha Cofradía en dicha Iglesia, o capilla de Nuestra Señora

6. L Lo sexto que todo lo que hay en la capilla casa y sacristía lo han de recibir por inventario: y si se fueren por algún accidente, o desamparen la dicha capilla y casa, han de entregar al cura que es o fuere de la dicha Parroquia del Hospital de los naturales todo lo que han recibido, y así mismo lo que en adelante, dieren por devoción, a Nuestra Señora para su culto y adorno, el Altar, o se hiciere con plata de su Coiradía: la cual entrega ha de ser en presencia del señor Provisor de este obispado que es o fuere o de quien su Iltma. ordenare, o sus sucesores, o sede vacante porque se continue la Iglesia o Capilla de Nuestra Señora de Almudena con el culto y devoción que hasta aquí se ha tenido

7.-Lo séptimo que se han de mantener contínuamente los dichos relígiosos Belemitas en buena y amigable corespondencia con los curas de la dicha Paroquia del Hospital de los naturales prestándose los unos a los biros, las alhajas y Conamentos" que hubieren me nester para sus iglesias y festividades. I no podrán dichos religiosos prestar nada de estas cosas que al presente se les han de entregar, a otras Iglesias o Conventos

8.-Lo octavo, que desde luego que tuvieren disposición de enfermería para dichos señores clérigos Sacerdotes y lo sufioiente para su curación y regalo han de poner, corriente dicha enfermería y lo propio se ha de ejecutar, en las que se han de tener para Indios convalecientes, aunque sea con las limosnas en lo que alcanzaren para dichos efectos según su Instituto, $y$ han de curar a dichos Sacerdotes en la casa que hay hoy en dicha Almudena, o adonde mejor estuvieren en la nueva fábrica y para ello han de correr dichos religiosos con las rentas que hoy tiene dicho Hospital de Sacerdotes y con las que en adelante tuviere según se dispondrá en la escritura que en este particular se ha de otorgar 
9.-Lo noveno, que todos los meses se ha de decír al principio de cada uno una Misa cantada de requiem con vigilia por su Iltma., y por el dicho Licenciado Don Ancirés de Mollinedo por haber edificado a su costa la dicha casa y capilla el dicho Don Andrés de Mollinedo

10.-Lo décimo que el primer patrón ha de ser su llima., y el segundq el dicho Licenciado Don Andrés de Mollinedo y después de éste lo han de ser Don Manuel Joseph de Mollinedo, su sobrino, hijo legítimo de su hermano legítimo el General Don Tomás de Mollinedo caballero del Orden de Santiago difunto y de doña Gabriela Josepha Palacios Azaña y Valdez su mujer: a quien han de seguir en dicho Patronato los hijos legítimos del dicho Don Manuel y sus descendientes; precediendo el mayor al menor: y el varón a la mujer: con calidad que sean legítimos y a falta cle esta descendencia ha de entrar en dicho Potronato Doña Juana de Mollinedo hermana legítima del dicho Don Manuel de padre y madre y a ésta han de suceder en el mismo derecho sus hijos y descendientes en la misma forma que va expresado, y si faltasen también de esta línea han de entrar por Patronos los que vinieren de España hijos legítimos y descendientes, también legítimos de Don Luis de Mollinedo Ortiz de Velasco hermano legítimo y mayor de los dichos Don Andrés y Don Tomás de Mollinedo y de su mujer Doña Agueda de Rado, y para entrar Con dicho Patronafo éstos, ha de ser suficiente para legitimae suscpersonas dainformación que trajeren hecha en España con su fe de Bautismo sin que s eles oblique, a ha. cer, otra en paraje tan remoto que el dicho Don Luis de Mollinedo fué vecino y natural del Real valle de Mena, en las montañas de Burgos de los Consejos de Bortedo y Santecilla, teniendo sus casas solariegas y infansonas en los pueblos de Bárcena y en el Barrio de la Quintana o del Berron de dichos Consejos: que hoy los posee su hijo seglar mayor Don Manuel Francisco de Mollinedo Ortiz de Velasco y cuando no se hallaren en estos Reinos del Perú, herederos en quienes deba legítimamente recaer este Patronato, como de suso se previene ha de poder heredarle los que se hallaren en los Reinos de Castilla, o en otras partes fuera de ellos $y$ justificaren deben ser sucesores y herederos de dicho Patronato: bastará para que lo reconozcan los Belemitas por legítimo y verdadero Patrón a aquel sujeto que les enviare información e instrumento competente de ser legítimo sucesor y faltando totalmente sucesión así varón como mujer de esta casa $y$ apellido extinguiéndose abso- 
Jutamente ha de recaer y recaiga dicho Patronato en los señores obispos que perpetuamente fueren de este obispado del Cuzco y sede vacante

Item que se han de poner las Armas del Rey Nuestro Señor en la capilla mayor en el mejor lugar y más patente sin embargo de estar puestas en la puerta de la Iglesia; y en otro lugar inferior la de su Iltma. con la sinsignias de obispo, como se acostumbre I porque ha de ser necesario fabricar de nuevo enfermerías para los señores Sacerdotes y convalecencia de Indios y OTRA IGLESIA COMO DE HECHO SE HA DADO PRINCIPIO, se declara que la Patrona de dicha nueva Iglesia, y Hospital ha de ser Nuestra Señora de la Almudena que hoy está en su capilla de la casa que se les ha de entregar $y$ se ha de colocar con su retablo en el Altar Mayor de dicha nueva Iglesia conservándola en lugar preeminente que hoy tiene como titular y Patrona, donde se han de continuar todas las condiciones y puntos qu econtuviere la escritura del Patronato que se ha de otorgar observando a la letra y reconociendo a IPatrón como tal, ejecutando sus cláusulas en la nueva Iglesia así en la dicha Iglesia como en todas las demás que perpetuamente se hicieren

Con las cuales dichas calidades y conduciones hacen y otorguen es. ta Donación y renuncian la ley de las Donaciones Inmensas y generales y la de los guiritientos sueldos aureosqueal Derecho permite que tan solamente se pueda donar por tener como tiene su Señoría lltma. en la rehta que le corre y bienes cuenta bastante para el lucimineto con que hasta aquí se portado y su familia secrún su digcon el dicho su beneficio según su estado y calidad. I por ser una obra tan pía y del servicio de Dios y de su agrado. Como dicho es $y$ haberse fabricado con este fin de que se emplease en cosa tan necesaria para el bien $y$ alivio así de dichos señores Sacerdotes pobres enfermos como en el de la convalescencia de Indios pues ha permitido su divina Magestad que en este tiempo en que gobierna su Iltma. se haya logrado su buen deseo, y el del dicho Licenciado Don Andrés de Mollinedo, en esta nueva fundación, y así. caso que esta donación excede de dichos quinientos sueldos aureos, otras tantas denociones vuelven a hacer de nuevo. con las mismas fuerzas y firmezas que éstas. I declaran que no es inmensa, ni general de todos sus bienes porque con el favor de Dios Nuestro Señor le quedan otros como dicho es: y por cuanto las donaciones para ser valederas han y deben ser insinuadas y legítimamente 
manifestadas, y para que ésta lo sea, la han por insinuada y legítimamente manifestada. I dan poder cumplido a dicho Rmo. Padre para que la presente ante cualquier Justicias y Jueces de su Magestad para que la insinuen $y$ hayan por insinuada e interpongan su autoridad según Derecho y se obligan a no rehusar reclamar ni contradecir por testamento codisilo, ni por otro ningún instrumento porque la hacen y otorgan de sus libres y expontáneas voluntades, y desde luego se desisten, quitan $\mathrm{y}$ apartan del Derecho y acción propiedad y señorío que a dicho santuario sus casas y a todo lo que le pertenece, habían y tenían y todo eljo lo ceden, renuncian y traspasan a dicha Hospitalidad de señores clérigos Sacerdotes enfermos y para dicha convalecencia de Inclios, y a dicha religión de Belemitas para dicho efecto para que dicho Rmo. Padre General en virtud de esta donación pueda tomar y aprehender la tenencia Y posesión del sitio, casas, santuario y demás bienes de Nuestra Señora de Almudena y en señal de poseción $y$ verdadera tradición otorgan esta escritura para que por ella o su traslado sea visto haberla adquirido sin otro acto alguno de aprehensión. I estando como dicho es presente a lo contenido en esta escritura el dicho Rmo. Padre General fray Rodrigo de la Cruz - otorgó que por sí y en nombre de sus sucesores y de la dicha Religión y Hospitalidad la acepta según y corno en ella se contiene y agradece a $S$. Iltma. la buena obra que por ellathace 8 al dichon Ligenciado Don Andrés de Mollinedo, su sobrino y que fía en su divina Magestad los premiará por obra "tan pía y es obliga por - Si y por los dichos sus sucesores a que guardarán, cumplirán y ejecutarán toda las calidades y condiciones susoferidas según como en ellas se contienen sin innovarlas ni alterarlas en cosa alguna de su tenor y forma -. 1 a la fírmeza y cumplimiento de lo que dicho es su Señoría Iltma. y el dicho Lizdo. Dn. Andrés de Mollinedo obligaron los bienes que conforme a Derecho pueden y deben obligar. I el dicho Rmo. Padre General fray Rodrigo de la Cruz los que conforme a sus Constituciones debe obligar, habídos $y$ por haber y para la ejecución de ello dieron poder cumplido a las Justicias y Jueces que conforme a Derecho de las causas de cada uno puedan conocer de cualesquier partes y lugares que sean para que a ello les compelan $y$ apremien como si esta escritura y lo que en ella contenido fuese sentencia pasada en autoridad de cosa juzgada, y han por suplido cualquier de fecto de requisito renunciación o solemnidad que para la mayor validación y cumplido efecto de esta escrítura se le quiera y así lo 
otorgaron y firmaron cura propio de la Parroquia de San Blas de esta ciudad consultor del Santo Oficio de la Inquisición en ella y su partido, el Lizdo. Don Juan Antonio de Iturrisarra cura rector de la Santa Iglesia Catedral y visitador de este obispado y el Doctor Don Sebastián de Mazedo cura propio de la Doctrina de Yaurisque en la Provincia de Chilques y Masques presentes -- Manuel obispo del Cuzco - Lizdo. Don Andrés de Mollinedo - Fray Rodrigo de la Cruz - Ante mí Pedro López de la Cerda escribano de su Ma. gestad y público.

El Rmo. Padre fray Rodrígo de la Cruz prefecto General del Orden de Belemitas. Parezco ante Vmd. Y digo que como consta de esta escritura que presento con el juramento necesario el Iltmo. señor Doctor Don Manuel de Mollinedo y Angulo obispo de esta ciudad del Cuzco y su obispado del Consejo de su Mágestad y el Lizdo. Dn. Andrés de Mollinedo su sobrino cura propio de la Parroquia del Hospital de los naturales y Comisario del Santo Oficio de la Inquisición en ella y su partido, hicieron donación intervívos del santuario y casa de Nuestra Señora de la Almudena que está en la otra banda de dicha Parroquia para la hospitalidad que se ha de fundar de señores clérigos Sacerdotes enfermos, y para la convalecencia de Indios. Con las calidades en ella contenidas las cuales se ha de servir Vmd. de haberla por insinuada y legítimamente manifestada e interponer en ella su autoridad y Decreto Judicial según Derechoparalsutnayor dralidación ayen su contormidad se me despache mandamiento de poseción para tomarla judicialmente de dicho santuario y casa $Y$ de todo lo que pertenecen. I me ampare y a la dicha mi religión en ella para no ser desposeído sin primero ser oído y por fuero y derecho vencido, por tanto -

A Vmd. pido y suplico que habiendo por presentada la dicha escritura se sirva de mandar hacer según y como pedido tengo con fusticia $y$ en lo necesario etc.

\section{Fray Rodrigo de la Cruz.}

Autos y vistos - dáse por presentada la donación que se refiere y sea por insinuada y legítimamente manifestada e interponía e interpuso $s$ uautoridad y Decreto Judicial en cuanto puede y con derecho debe para su mayor validación y que irá personalmente su mrd. a dar poseción la Rmo. Padre tray Rodrigo de la Cruz prefecto General del Orden de Belmitas del santuario y casa de Nuestra Señora de la Al- 
mudena y de todo lo anejo $\mathrm{y}$ perteneciente a ella en virtud de la dicha donación sin jerjuicio de tercero gue mejor lo tenga.

D. Juan Fernando Calderón de la Barca.

Proveído lo de suso decretado por el señor Don Juan Fernando Calderón de la Barca caballero del orden de Calatrava del Consejo de su Magestad y su alcalde de corte más antiguo de la Real Audiencia de la ciudad de los Reyes Justicia Mayor en esta del Cuzco por su Mages. tad a primero día del mes de septiembre de mil y seicientos y noventa $\mathrm{y}$ ocho años.

Ante mí

Pedro de la Cerda.

Escribano de su Mageslad y público.

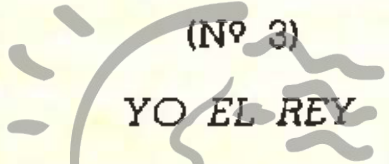

Al Reverendo Ynrplo. Padre obispo de la Iglesia Catedral de la ciudad del Cuzco en las provincias del Perú, de mi Consejo. Hace recibido vuestra carta de 10 de mayo del año pasado de 1696 en que proponeis, conceda licencia para fundar Hospital de convalecientes en esa ciudad a los Biernanos de lad Compatía Bethlemítica, por no haberle en ella para los Indios, proponiendo por muy a propósito para este ministerio la "Casace Iglesfa de Nuestra Senora de la Almudena, que tiene oficinas suficientes para Hospital, y curación de Sacerdotes pobres, debiendo los medios que aplicariádes a su manutención, y habiéndose visto en mi Consejo de Indias, he venido en conceder la licencia que pedís para la fundación de Hospital de convalecientes en ella, que esté a cargo de los Religiosos Bethlemitas, con calidad de que el Patronato Real, no sea perjudicado, y quedando debajo de la Real protección, y con las mismas condiciones que están prevenidas en las demás fundaciones de Hospitales de esos Reynos. De que estareis advertido para que se ejecute en esta conformidad. De Madrid a 17 de agosto de 1700.

YO EL REY.

Por mandato del Rey nuestro

Señor.

D. Domingo de Calo y Mondragón. 